\title{
EARLY INTERVENTION PROGRAMME FOR PATIENTS WITH PSYCHOTIC DISORDERS IN "SVETI IVAN". PSYCHIATRIC HOSPITAL (RIPEPP) - SOCIODEMOGRAPHIC AND BASELINE CHARACTERISTICS OF THE PARTICIPANTS
}

\author{
Branka Restek-Petrović ${ }^{1,2}$, Ana Majdančić ${ }^{1}$, Sven Molnar ${ }^{1}$, Majda Grah ${ }^{1}$, Ena Ivezić ${ }^{1}$, Igor Filipčići ${ }^{1,2,3}$, \\ Anamarija Bogović ${ }^{1,4}$, Vladimir Grošić ${ }^{1}$, Nina Mayer ${ }^{1}$, Slobodanka Kezić ${ }^{1}$ \& Irena Pavlović ${ }^{1}$ \\ ${ }^{I}$ Psychiatric Hospital "Sveti Ivan", Zagreb, Croatia \\ ${ }^{2}$ Faculty of Medicine, Josip Juraj Strossmayer University of Osijek, Osijek, Croatia \\ ${ }^{3}$ School of Medicine, University of Zagreb, Zagreb, Croatia \\ ${ }^{4}$ Department of Psychology, Catholic University of Croatia, Zagreb, Croatia
}

received: 11.6.2016;

revised: 29.11.2016;

accepted: 17.1.2017

\section{SUMMARY}

Background: Psychiatric hospital "Sveti Ivan" in Zagreb, Croatia, offers an outpatient Early intervention programme for patients with psychotic disorders (RIPEPP), consisting of psychoeducational workshops and group psychodynamic psychotherapy. The aim of this study was to describe sociodemographic and baseline characteristics of the participants, in order to provide better understanding of this population, and to assist with the development of more effective therapeutic approaches.

Subjects and methods: Since 2008, a total of 245 patients with first episodes of psychosis and their family members participated in the programme. They filled out several questionnaires within the framework of the programme evaluation, but for the purposes of this study, only data collected on sociodemographic questionnaire and the Health of the Nation Outcome Scales (HoNOS) are presented.

Results: Majority of the participants were male (66\%), at the average age of 28 (SD=6.6), living with their parents (73.5\%). Most of them finished secondary school (45.7\%) but almost a quarter of the sample (23.7\%) is currently studying at university. The average duration of untreated period was 101.60 days, with a median of 30 days. According to results of HONOS questionnaire, upon entry into the programme, the patients most often listed cognitive functioning (attention, concentration, memory) and professional issues (performance of work tasks and activities tied to work) as the most problematic areas.

Conclusion: The findings of this study provide more detailed description of the beneficiaries of the RIPEPP programme, which can contribute to forming future programmes for the prevention of psychotic disorders.

Key words: early intervention - psychosis - baseline characteristics

\section{INTRODUCTION}

Psychotic disorders affect virtually $3.4 \%$ of the population during the lifespan (Perala et al. 2007), and $80 \%$ of cases first appear during the adolescent period (van Os \& Kapur 2009). The risks for the appearance of nonaffective psychosis approaches $1 \%$ during the lifespan, which represents a significant source of suffering for those affected and their families, and an enormous financial burden for the health care and social welfare systems (Mangalore \& Knapp 2007). Despite new medications and the development of community mental health services, those suffering from schizophrenia display a range of long-term outcomes (Mason et al. 1997). Prospective studies of patients with first psychotic episodes show that patients often have a suboptimal response to the applied intervention, with a poor outcome in $30 \%$ of cases, a good outcome in $40 \%$ of cases, while symptomatic and social recovery is seen in fewer than $20 \%$ of cases after a two-year monitoring period (Wunderink at al. 2009). The long duration of untreated psychosis (DUP) is responsible for $30 \%$ of this heterogeneity (Marshall et al. 2005). Social disabilities develop already in the prodromal phase, such that the "critical period" (Birchwood et al. 1998) in which disabilities are formed and fixed. It is a period of key focusing on preventative efforts and evidence-based interventions.

Broadly coordinated, scientifically and expertly led international efforts, directed at reforming the therapeutic approach and at organising mental health services for patients with initial psychotic episodes, have achieved common guidelines, thus laying the foundation for the broad development of early intervention programmes (Insell 2007, 2009). Thus, since the 1980s, we have witnessed the development of a number of different early intervention programmes in Europe, Australia, North America and Asia that aim to provide adequate care and treatment for the population of psychotic patients in the early phases of the disorders (McGorry et al. 2010). The organisation of this new "clinical infrastructure" has enabled an accumulation of evidence that early diagnosis and highly professional early therapy is of fundamental significance in psychiatry. Though there is still no consensus on the optimal duration or type of intervention, the evidence has suggested this approach is the most promising. In line with this, guidelines have been 
published for clinical practice and consensus statements (McCrone et al. 2007, McGorry et al. 2007, McCrone et al. 2008), and the concepts and development of early intervention were supported by the US National Institutes of Health and included in the UK National Institute for Health and Care Excellence (NICE) guidelines. In the UK, the Schizophrenia Commission assessed it as the most significant advancement in the field of mental health care since the inception of community psychiatry (Birchwood 2014).

Despite these positive development processes, its implementation has been very slow, and many patients in the early phases of psychosis still do not have access to optimal, evidence-based and efficient care (McGorry et al. 2010).

Research of psychotic disorders often has varying limitations, ensuing from the difficulty of encompassing the complete population of psychotic patients. For example, the requirement for the use of informed consent excludes uncooperative patients, which reduces the possibility of generalising results and leads to inadequate conclusions. For this reason, studies on first psychotic episodes based on the entire population of a given region are particularly valuable (Conus et al. 2007).

\section{Early intervention programme for psychotic disorders at the Sveti Ivan Psychiatric Hospital}

In Croatia, community mental health service is still in its infancy. Patient care is typically provided in large psychiatric hospitals, and generally there are no specialised outpatient programmes for patients with first psychotic episodes or for patients with prodromal symptoms (Molnar et al. 2009). Furthermore, there is a lack of systematic research on this population, their sociodemographic characteristics, duration of untreated psychosis (DUP), adherence to therapy and treatment outcomes. One of the indicators for the efficacy of prevention and the outcomes of the disorder is the number of days since the appearance of the disorder, referred to as the duration of untreated psychosis (DUP). Nishii et al. (2010) stated that the DUP is one of the future quantitative benchmarks of general mental health, as it enables a comparison of different countries on the issue of secondary prevention in the psychiatry.

In 2005, the personnel, professional, scientific, organisational, spatial and material capacities of Sveti Ivan Psychiatric Hospital were examined in order to conceive and begin implementation of a treatment programme for patients in the early phases of psychotic disorders (RIPEPP programme). This is a comprehensive therapy programme for treatment and support to patients affected by psychotic disorders and their family members. The programme includes patients in early phases of psychotic disorders treated both at the hospital and in outpatient treatment, which are within the "critical period" of five years from the first appearance of psychotic symptoms.
In defining the concept of the programme, an important contribution was received from the experiences of the leading global early intervention programmes (OPUS (Bertelsen at al. 2008), LEO study (Craig at al. 2004), DNSP (Lindhart 2008), EPPIC (Henry et al. 2010), TIPS (Larsen at al. 2006)), and of participation in world congresses, particularly those organised by ISPS (International Society for Psychological Treatments of Psychoses) and IEPA (International Early Psychosis Association). Many years of experience in the hospital and outpatient psychotherapeutic work with psychotic patients was integrated into the programme, resulting in the formation of a Reference Centre for Psychotherapy, Psychosocial Methods and Early Intervention for Psychotic Disorders of the Croatian Ministry of Health and Social Welfare in this hospital in 2006 (RestekPetrović et al. 2008). The expert team at the Sveti Ivan Psychiatric Hospital has theoretically formulated the fundamental concept of the RIPEPP programme, whose objectives are secondary and tertiary prevention, and the development of psychopharmacological, psychotherapeutic and psychosocial approaches to the population of young patients (Restek-Petrović et al. 2008, 2012).

The RIPEPP programme encompasses several therapeutic activities:

- Psychoeducation - carried out in a series of 15 interactive workshops led by psychiatrists, cognitivebehavioural therapists, with the cooperation of psychiatrists who are group analysts. The 60-minute workshops are intended for patients and their family members and are held every two weeks as a large open, task-oriented group. The workshop topics vary and cover a wide spectrum of information on the disease symptoms, their aggravation, ways of monitoring, pharmacotherapy, relapse prevention etc. (Molnar et al. 2010).

- Psychodynamic group psychotherapy - intended for patients, these 60-minute sessions are held once a week, under the therapeutic guidance of a psychiatrist group analyst and a psychiatry resident.

- Psychodynamic group psychotherapy for family members - intended for family members of patients included in the RIPEPP programme that are motivated for psychological work and the correction of maladaptive forms of family interactions. The 90minute sessions are held every two weeks under the guidance of a psychiatrist group analyst.

The objective of this paper was to describe the population of patients encompassed in the programme on their sociodemographic and clinical characteristics, as well as on their health and social status. A more detailed description of the beneficiaries of the RIPEPP programme will provide better understanding of the population of patients treated for first episodes of psychotic disorders, with the purpose of further development of the RIPEPP programme, and of contribution to forming future programmes for the prevention of psychotic disorders. 


\section{SUBJECTS AND METHODS}

\section{Subjects}

Since 2008 , a total of 245 patients with the first episodes of psychotic disorders, and their family members, participated in the RIPEPP programme. The programme included hospitalised patients with acute psychotic disorders, schizophrenia, schizoaffective disorder and bipolar affective disorder with psychotic symptoms, diagnosed according to the criteria of the ICD-10 classification system. All the patients received pharmacotherapy, primarily with atypical antipsychotics, based on the principle "start low and go slow". After the establishment of initial stabilisation of the mental state, patients were included in psychotherapy and sociotherapy programme in the open ward. During their hospital stay, patients started the psychoeducational part of the RIPEPP programme, together with their family members. Upon their discharge, motivated patients and their family members continued psychoeducation and were also included in other therapeutic activities within the programme. Those who were not motivated to take part in the offered group psychotherapy treatment or who did not meet the inclusion criteria (patients with comorbidity of addiction, neurological deficits, or lower mental capacities were not included) participated in sociotherapeutic and psychosocial activities.

\section{Instruments and procedure}

Upon inclusion in the RIPEPP programme, every patient and their family members filled out a battery of questionnaires, within the framework of the programme evaluation. These instruments were completed under the assistance and guidance of the expert staff. For the purposes of this study, only data collected on sociodemographic questionnaire and The Health of the Nation Outcome Scales (HoNOS) was examined.

The sociodemographic questionnaire consisted of questions relating to: gender, age, education level, marital status, housing conditions, sources of income, reason for admittance to the hospital, inclusion in the programme, duration of untreated psychosis (DUP), type of diagnosis upon inclusion in the programme, and information on their social functioning.

The Health of the Nation Outcome Scales (HoNOS) measure the level of health and social functioning of persons suffering from serious mental disorder. It is intended to be an instrument for monitoring and evaluation of treatment. A series of studies (eg. Preti et al. 2012) outlined adequate psychometric characteristics of the questionnaire. It consists of 12 items measuring behavioural issues (overactive, aggressive, disruptive or agitated behaviour, non-accidental self-injury, problem drinking or drug-taking), cognitive or somatic impairment, symptoms (hallucinations and delusions, depressed mood, other mental or behavioural problems) and social functioning (problems with relationships, occupations, activities in daily living and living conditions). The items are rated from 0 (no problem) to 4 (severe problem). The results can be shown individually for each item or as the total result. The total result can range from 0 (best score) to 48 (worst score). HoNOS was developed by the Royal College of Psychiatrists (UK) at the request of the UK Health Ministry in 1993 (Jacobs 2009).

\section{Statistical analysis}

Data analysis was performed using SPSS (Statistical Package for the Social Sciences), version 16. Descriptive statistics was used in order to present the sociodemographic, clinical and other characteristics of the patients. Data are presented in tables and figures. The association between the DUP and the results obtained on HoNOS was determined using Spearman rho correlation coefficient.

\section{RESULTS}

In the period from 2008-2013, a total of 245 patients were included in the RIPEPP programme (66\% men). The average age of patients was 28.28 years $(\mathrm{SD}=6.60)$ for men and $28.85(\mathrm{SD}=7.51)$ for women. This difference was not statistically significant $(\mathrm{t}=0.612, \mathrm{p}=0.541)$. Age ranged from 18 to 51 years, with the highest frequency of patients aged 24 and 26 years. The most frequent diagnoses were acute psychotic disorder $(69.4 \%)$ and schizophrenia (18.8\%). Other diagnoses were as follows: schizoaffective disorder $(3.7 \%)$, schizotypal disorder $(2.4 \%)$, bipolar disorder $(2 \%)$, derangement disorder $(1.2 \%)$, undetermined inorganic psychotic disorder $(0.8 \%)$, psychotic syndrome caused by drugs/alcohol $(0.4 \%)$, other $(0.8 \%)$.

The majority of patients included in the RIPEPP programme have completed secondary school (45.7\%), while $10.2 \%$ have completed university (Figure 1). It is also important to state that almost a quarter of the sample $(23.7 \%)$ were currently studying at university.

Figure 2 shows that the majority of patients included in the RIPEPP programme lived with their parents $(73.5 \%)$, while $8.6 \%$ lived with their spouse and children. At the time of inclusion into the programme, $86.1 \%$ stated that they were not in an emotional relationship.

One of the main criteria for inclusion into the RIPEPP programme is that the patient is within the "critical period" of the disorder, i.e. within the first five years since the appearance of the first psychotic symptoms. Therefore, the data on the number of days since the appearance of the first psychotic symptoms to the start of treatment (DUP=duration of untreated psychosis) was collected upon inclusion into the programme. In the population of patients included in the RIPEPP programme, DUP (shown as the arithmetic mean) was 101.60 , with a median of 30 days. Table 1 shows the 
Table 1. Overview of the frequency of days from the first appearance of psychotic symptoms to the start of treatment (DUP)

\begin{tabular}{|c|c|c|c|}
\hline $\begin{array}{l}\text { Number of } \\
\text { days }\end{array}$ & Frequency & Percentage & $\begin{array}{l}\text { Cumulative } \\
\text { percentage }\end{array}$ \\
\hline 0 & 5 & 2.0 & 2.1 \\
\hline 1 & 25 & 10.2 & 12.8 \\
\hline 2 & 7 & 2.9 & 15.8 \\
\hline 3 & 8 & 3.3 & 19.2 \\
\hline 4 & 4 & 1.6 & 20.9 \\
\hline 5 & 2 & 0.8 & 21.8 \\
\hline 7 & 30 & 12.2 & 34.6 \\
\hline 8 & 1 & 0.4 & 35.0 \\
\hline 10 & 9 & 3.7 & 38.9 \\
\hline 11 & 1 & 0.4 & 39.3 \\
\hline 14 & 16 & 6.5 & 46.2 \\
\hline 15 & 2 & 0.8 & 47.0 \\
\hline 21 & 3 & 1.2 & 48.3 \\
\hline 25 & 1 & 0.4 & 48.7 \\
\hline 30 & 37 & 15.1 & 64.5 \\
\hline 45 & 1 & 0.4 & 65.0 \\
\hline 50 & 1 & 0.4 & 65.4 \\
\hline 60 & 12 & 4.9 & 70.5 \\
\hline 75 & 1 & 0.4 & 70.9 \\
\hline 90 & 16 & 6.5 & 77.8 \\
\hline 120 & 5 & 2.0 & 79.9 \\
\hline 150 & 2 & 0.8 & 80.8 \\
\hline 180 & 6 & 2.4 & 83.3 \\
\hline 187 & 1 & 0.4 & 83.8 \\
\hline 240 & 1 & 0.4 & 84.2 \\
\hline 270 & 1 & 0.4 & 84.6 \\
\hline 300 & 1 & 0.4 & 85.0 \\
\hline 365 & 24 & 9.8 & 95.3 \\
\hline 547 & 1 & 0.4 & 95.7 \\
\hline 730 & 10 & 4.1 & 100.0 \\
\hline Total & 234 & 95.5 & \\
\hline Missing & 11 & 4.5 & \\
\hline Total & 245 & 100.0 & \\
\hline
\end{tabular}

frequency of the number of days of DUP. This table shows that the first psychotic symptoms most often appear within 30 days or within 7 or 365 days prior to the start of treatment, which is possibly a recording artefact since patients and clinicians estimate retrospectively how long symptoms began.

According to the results, $88 \%$ of patients were included in the programme at the recommendation of psychiatrists from the Sveti Ivan Psychiatric Hospital. About $26 \%$ of patients were in outpatient treatment prior to inclusion in the programme, and about $57 \%$ had previously been hospitalised. For $40 \%$ of patients, the time of inclusion into the programme was during the period of the first hospitalisation. The circumstances of the admittance to hospital were as follows: $42 \%$ of the patients were accompanied by persons close to them, $30 \%$ were brought by ambulance, $19 \%$ were brought by ambulance and accompanied by the police, and $9 \%$ of patients were forcefully retained. It should also be noted that $24 \%$ of patients reported that after their first treatment, they stopped taking pharmacotherapy.

The results of the HoNOS questionnaire were also examined. The average result for the patients was 14.82 $(\mathrm{SD}=8.48)$. The data for the parents are not provided in this paper, since the majority of parents did not fill out the questionnaire. This is likely due in part to a lack of trust in the usefulness of the collected data, and partly to the general lack of motivation for inclusion into the programme. The HoNOS questionnaire measures the level of health and social functioning of persons suffering from mental disorders. Upon entry into the programme, the patients most often listed cognitive functioning (attention, concentration, memory) and area of professional issues (relates to the performance of work tasks and activities tied to work) as the most problematic areas (Table 2).

Table 2. The results of the patients included in the RIPEPP programme on the HoNOS questionnaire

\begin{tabular}{|c|c|}
\hline & $\begin{array}{l}\text { patients } \\
* \mathrm{M}(\mathrm{SD})\end{array}$ \\
\hline Total HoNOS result & $14.82(8.48)$ \\
\hline \multicolumn{2}{|l|}{ HoNOS questionnaire subscales } \\
\hline Behavioral problems & $2.17(2.22)$ \\
\hline Cognitive and somatic damage & $2.06(1.57)$ \\
\hline Symptoms & $4.72(3.44)$ \\
\hline Social functioning & $6.37(4.37)$ \\
\hline \multicolumn{2}{|l|}{ Individual scales of the HoNOS questionnaire } \\
\hline $\begin{array}{l}\text { Overactive, aggressive, disruptive } \\
\text { or agitated behavior }\end{array}$ & $1.38(1.43)$ \\
\hline Non-accidental self-injury & $0.36(0,96)$ \\
\hline Problem drinking or drug-taking & $0.43(0.97)$ \\
\hline $\begin{array}{l}\text { Cognitive problems } \\
\text { (concentration, attention, memory) }\end{array}$ & $1.92(1.43)$ \\
\hline Physical illness or disability problems & $0.14(0.57)$ \\
\hline $\begin{array}{l}\text { Problems associated with hallucinations } \\
\text { and delusions }\end{array}$ & $1.32(1.55)$ \\
\hline Problems with depressed mood & $1.60(1.43)$ \\
\hline Other mental and behavioural problems & $1.80(1.62)$ \\
\hline Problems with relationships & $1.55(1.49)$ \\
\hline Problems with activities of daily living & $1.36(1.47)$ \\
\hline Problems with living conditions & $1.69(1.55)$ \\
\hline Problems with occupation and activities & $1.77(1.55)$ \\
\hline
\end{tabular}

The association of the obtained results of the HoNOS questionnaire and DUP was also examined. Namely, the question was posed as to whether a longer DUP would also mean a higher HoNOS score (in the sense of more pronounced disturbances in the overall health and social functioning). The results showed a statistically significant correlation (Spearman's rho $=0.213, \mathrm{p}=0.01$ ): longer DUP is associated with more pronounced symptoms. 


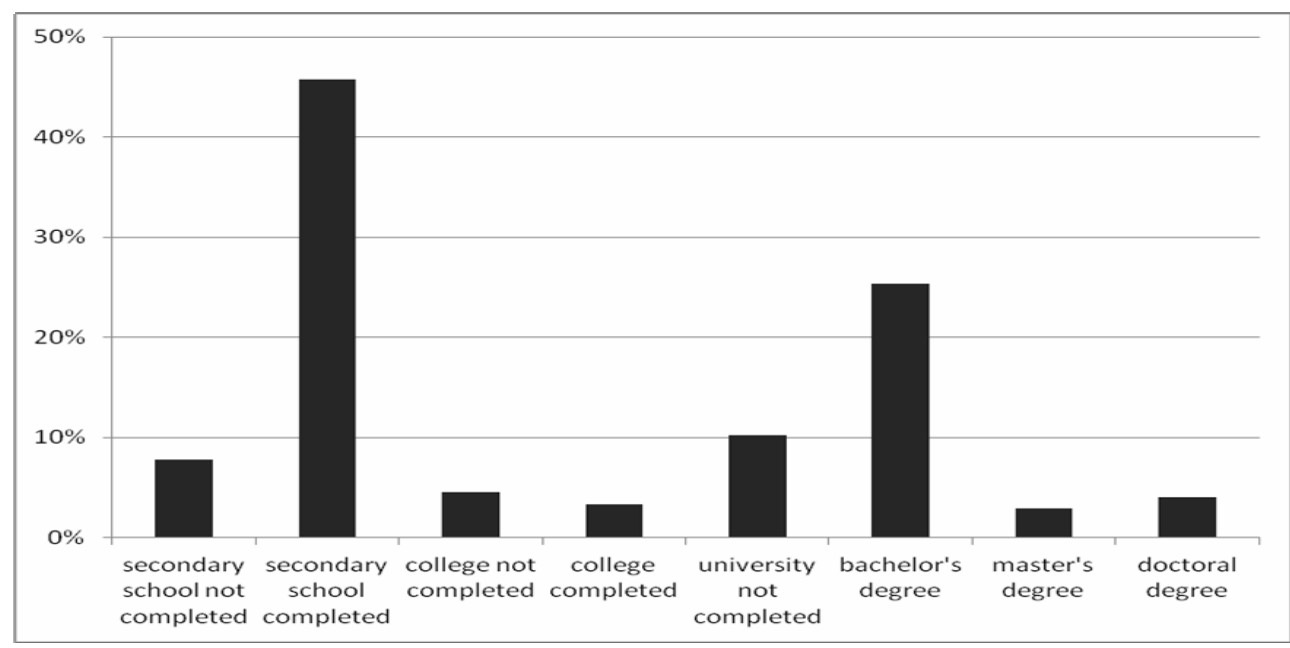

Figure 1. The educational level of patients included in the RIPEPP programme $(\mathrm{N}=245)$

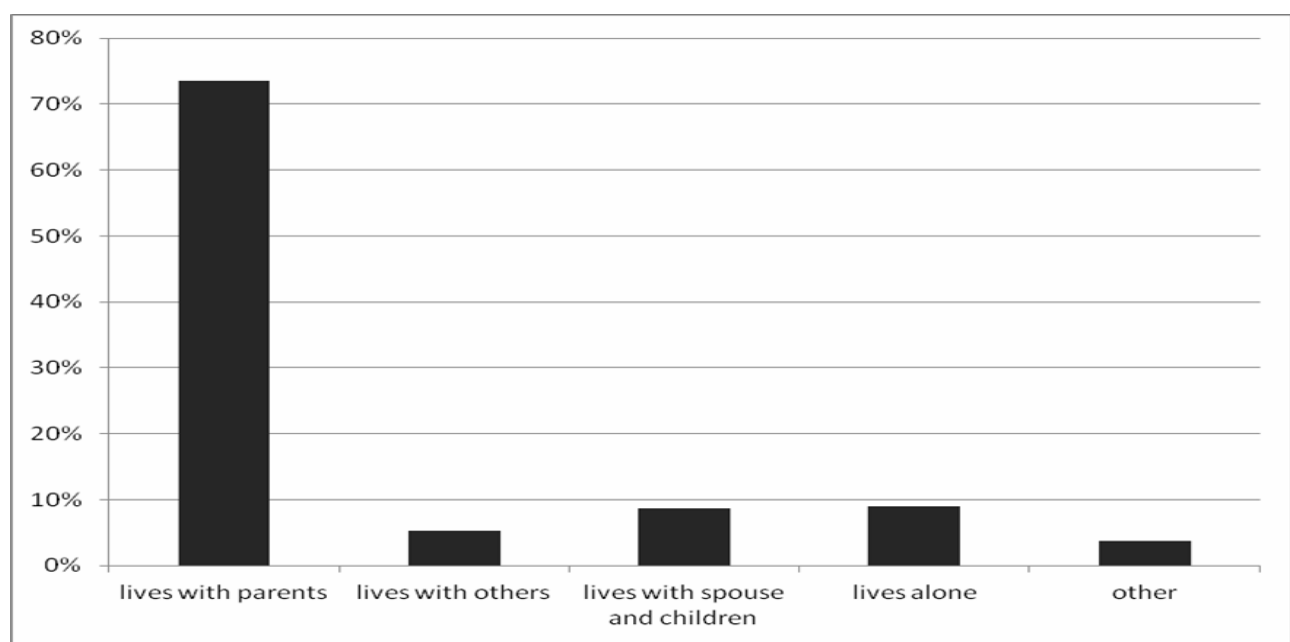

Figure 2. Living situation of patients included in the RIPEPP programme $(\mathrm{N}=245)$

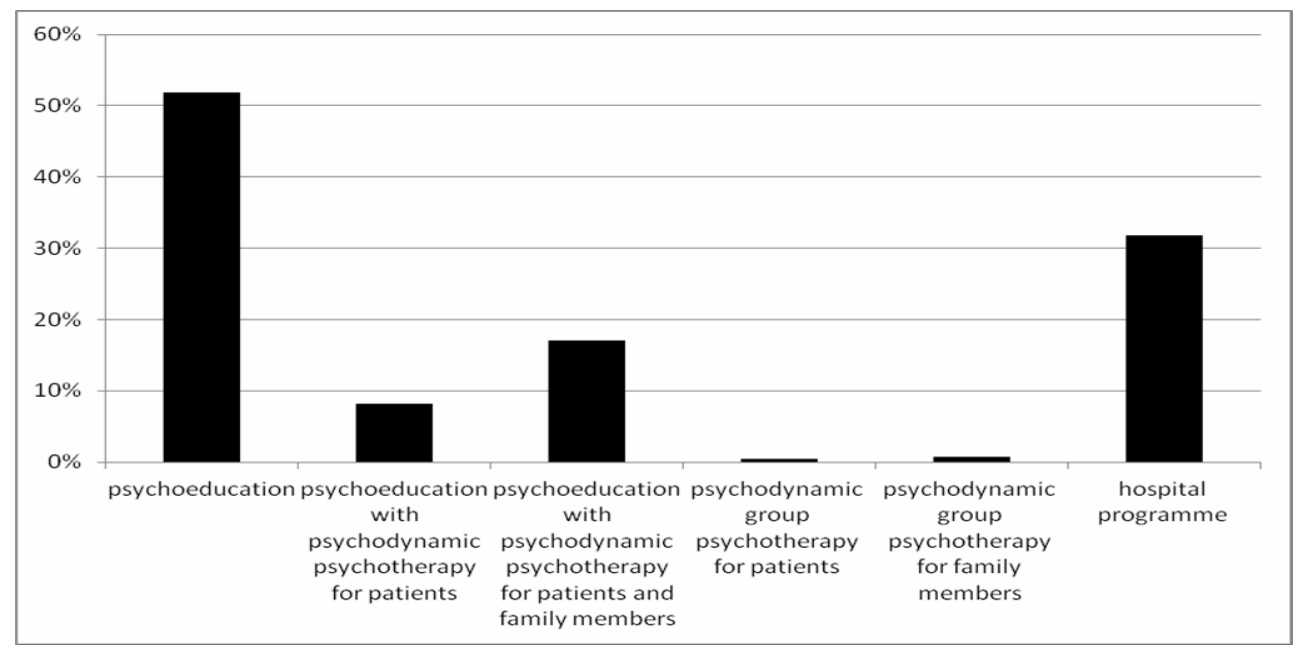

Figure 3. Overview of the percentage of participation of patients and their family members in all the content offered within the RIPEPP programme

Considering that the RIPEPP programme offers a series of content for patients and their family members, the percentage of participation by content is shown graphically in Figure 3. It is evident that the most patients participated in psychoeducation and hospital programmes, while $17 \%$ of patients participated in psychoeducation and psychodynamic group psychotherapy. Meanwhile, their parents participated in psychodynamic group psychotherapy intended for family members. 


\section{DISCUSSION}

The results describe the sociodemographic and baseline characteristics of the population included in the RIPEPP early intervention programme for psychotic disorders. From the results shown, it is evident that the majority of the population were males, with an average age of 28 years, though the majority of participants were between 24 and 26 years old. In line with the younger age, the majority of patients still lived with their parents, and a quarter of them were studying at university. These data indicate that future prevention programmes should be directed more towards the younger population, especially younger men.

The findings on clinical characteristics of the patients indicate gravity of the clinical signs and symptoms that were cause for hospitalisation. Namely, about half of the patients were hospitalised as emergency cases, and brought in by ambulance, of which a portion $(19 \%)$ were accompanied by police. This data rises a concern about the new act on the protection of persons with mental issues. Namely, a higher degree of human rights protection is introduced for patients when deciding on their treatment consent and type of psychiatric care. Meanwhile, there is a lack of adequate psychiatric services in the community intended for caring for patients with initial episodes of psychotic disorders. This could contribute to the delay of treatment, thereby causing a negative outcome of the disease. If the majority of patients are accompanied by emergency medical teams, this suggests the severe condition of the patient (who are very often uncritical towards their own conditions, untrusting of experts and often resisting pharmacotherapy).

The delay of the necessary treatment harms patients, considering that it is known that the patients' condition and further prognosis is largely dependent on the duration of untreated psychosis (DUP). Some researchers have associated a longer DUP period with an increased number of severe symptoms and poorer quality of life (Harris et al. 2005) while some studies stress that a longer DUP is associated with difficulties in the social and psychological spheres (Barnes et al. 2008). In this paper, DUP is defined as the number of days from the appearance of the first psychotic symptoms, to the introduction of pharmacotherapy. The results of this study showed a wide range of DUP, with an average of 101.6 days and a median of 30 days. In comparison, one can consider the data from the TIPP (Treatment and Early Intervention in Psychosis Program) programme, conducted at the Psychiatry Ward of the University Hospital at Lausanne, Switzerland (Polari et al. 2011). This study defined the DUP in three different ways, i.e. as the number of months from the start of psychotic symptoms to the start of application of pharmacotherapy (DUP1 $=2.2$ months), as the number of months from the start of psychotic symptoms to the inclusion in the programme (DUP2 $=7.4$ months), and as the number of months from the start of the psychotic symptoms to the inclusion in the programme and application of pharmacotherapy though with a poor general outcome (DUP3=13.6 months). Though these two programmes are not comparable due to their varying activities, it is possible to see that the DUP in the RIPEPP programme is somewhat longer than the DUP1 measured in the TIPP programme in Switzerland. However, several surveys (Malla et al. 2002, Sheitman et al. 2006) stress that the application of the treatment within the first six months is crucial in predicting the further course of the disease, and the general development of symptoms.

Two comprehensive meta-analyses (Marshall et al. 2005, Perkins et al. 2005) showed that a long duration of untreated psychosis is associated with a poor outcome of the disorder. The Scandinavian TIPS study (The Early Treatment and Identification of Psychosis; Larsen et al. 2006, Melle et al. 2008) showed that a reduced DUP, with the education of professionals and the public, and quick and easily accessible therapeutic intervention in early stages of the disorder positively influenced the outcome. In line with these findings, the results of our study indicate statistically significant negative correlation between DUP and the level of health and social functioning of the patients. Since almost one-quarter of the sample is currently studying at university, the association between DUP and cognitive efficacy should be especially noted. Gaynor et al. (2009) showed that if the DUP is reduced to a period of less than six months, this will lower the risk of a significant drop of intellectual efficacy. Since patients themselves expressed a significant presence of difficulties in the area of cognitive functioning, future early intervention programmes should be supplemented by various forms of cognitive rehabilitation (Restek-Petrović et al. 2014). The importance of reducing DUP is also supported by brain NMR studies, where the loss of grey matter was found during the prodromal period and in the first episode of psychosis. The studies have shown that damage of brain structures and its plasticity appear in the later prodromal period and at the start of the first psychotic episode (Pantelis et al. 2003, Koutsouleris et al. 2009, Meizenzahl et al. 2008a, 2008b).

The length of DUP of patients included in the RIPEPP programme on average fell within the critical period of 6 months from the start of symptoms, which would predict a better response to overall treatment, and with that a better prognosis. It should be stated that the data in this paper refer to the population of Croatia's capital city, where the accessibility and availability of psychiatric services is higher than in other parts of Croatia, for which there are no data on the DUP. Also, it is possible that longer DUP patients were not being picked up by the service. Thus, our sample may not adequately represent the general population of patients. 
The majority of participants in the programme were included in hospital programmes or psychoeducation offered to patients during and after the time of their treatment in hospital. On the other hand, only a few participants signed up for group psychotherapy for patients and group psychotherapy for family members, which is an important indicator of the motivation and overall attitude of patients and their family members towards long-term engagement and continued treatment. Namely, the psychotherapeutic groups demand a higher degree of motivation and involvement, for which many patients in the early phases of psychotic disorders are not yet ready (Restek-Petrović et al. 2009, Restek- Petrović et al. 2010).

Alongside the standard psychiatric care available to patients throughout the country, there is a lack of specialised programmes, especially for outpatients, and therefore a lack of opportunities to prevent the development of psychotic disorders. Often this is the reason why affected persons do not receive help on time, which further intensifies symptoms. Family members, left to deal with the situation and to seek help on their own, are often exhausted and overwhelmed by the emotional and economic burden. For this reason, it is imperative to enable the appropriate development of community psychiatry (via a specialist and trained teams) that would assist those affected and their families in their local environment. The Declaration on Early Psychoses, first presented at the Youth Mental Health Summit in 2010 and published to date in Ireland and Great Britain, emphasizes the significance of raising awareness in society among families and youth (aged 12-25 years) on mental health, and the importance of including youth and families in planning and designing mental health projects (Coughlan et al. 2013). There is an urgent need for clearer and more systematic society care for persons with mental health issues.

There are several limitations to the current study that need to be mentioned. First, the sample of the patients is specific in its sociodemographic and clinical characteristics, due to the program inclusion criteria and differences in patients motivation for participation in the treatment, which limits the generalization of our findings. The second limitation of this study stems from its reliance on self-report measure (HoNOS) that is susceptible to subjectivity. Unfortunately, the data gathered from the parents could not be provided in this paper, since the majority of parents did not fill out the questionnaire. Also, this is the only one instrument used to measure the level of health and social functioning of the patients. Future studies are encouraged to apply a broader set of measures and a multi-method strategy for gathering data (e.g., interviews, observations, reports both from family members and the attending medical staff).

\section{CONCLUSIONS}

This study contributes to more detailed description of the beneficiaries of the RIPEPP programme, and provides better understanding of the population of patients treated for first episodes of psychotic disorders. The majority of these patients were younger men, single and still living with their parents. They were mostly in severe condition when they were hospitalized and included in the programme. Furthermore, the findings showed a wide range of duration of untreated period (DUP), with an average of 101.6 days, that was negatively correlated with the level of health and social functioning of the patients. Upon entry into the programme, the patients most often listed cognitive functioning and area of professional issues as the most problematic areas. Concerning their participation in the programme, the lack of motivation for long-term engagement was observed. There is a great need for specialized programmes, especially for outpatients, and hopefully these findings will contribute to development of more effective therapeutic approaches.

\section{Acknowledgements: None.}

Conflict of interest: None to declare.

\section{Contribution of individual authors:}

Branka Restek Petrovic was involved with study design, data interpretation, and manuscript preparation.

Ana Majdancic performed data collection and statistical analyses, and was involved in the writing of the manuscript drafts.

Sven Molnar, Majda Grah, Vladimir Grosic, Nina Mayer, Slobodanka Kezic \& Irena Pavlovic participated in data collection and manuscript preparation.

Ena Ivezic \& Anamarija Bogovic participated in data interpretation, and in the writing and multiple edits of the manuscript drafts.

Igor Filipcic was involved with study design, and reviewed the manuscript drafts.

\section{References}

1. Barnes TRE, Leeson VC, Mutsatsa SH, Watt HC, Hutton $S B$ \& Joyce EM: Duration of untreated psychosis and social function: 1 year follow up study of first episode schizophrenia. Br J Psychiatry 2008; 193:203-9.

2. Bertelsen $M$, Jepessen $P$, Petersen L, Thorup A, Ohlenschlaeger J, Le Quach P et al.: Five-year follow up of a randomised multicenter trial of intensive early intervention versus standard treatment for patient with a first episode of psychotic illness: the OPUS trial. Arch Gen Psychiatry 2008; 65:762-71. 
3. Birchwood M, Todd P \& Jackson C: Early intervention in psychosis. The critical period hypothesis. Br J Psychiatry 1998; 172:53-9.

4. Birchwood M: Early intervention in psychosis services: the next generation (editorial). Early Interv Psychiatry 2014; 8:1-2.

5. Conus P, Cotton S, Schimmelmann B G, MGorry PD \& Lambert M: The First-Episode Psychosis Outcome Study: premorbid and baseline characteristics of an epidemiological cohort of 661 first-episode psychosis patients. Early Interv Psychiatry 2007; 1:191-200.

6. Coughlan H, Cannon M, Shiers D, Power P, Barry C, Bates $T$ et al.: Towards a new paradigm of care: the International Declaration on Youth Mental Health. Early Interv Psychiatry 2013; 7:103-8.

7. Craig TK, Garety $P$, Power P, Rahaman N, Colbert $S$, Fornells-Ambrojo $M$ et al.: The Lambeth Early Onset (LEO) Team: randomised controlled trial of the effectiveness of specialised care for early psychosis. BMJ 2004; 329:1067.

8. Gaynor K, Dooley B, Lawlor E, Lawoyin, LR \& O'Callaghan E: Cognitive deterioration and duration of untreated psychosis. Early Interv Psychiatry 2009; 3:157-60.

9. Harris MG, Henry LP, Harring SM, Purcell R, Schwartz $O S$, Farrely $S E$ et al.: The relationship between duration of untreated psychosis and outcome: An eight-year prospective study. Schizophr Res 2005; 79:85-93.

10. Henry LP, Amminger GP, Harris MG, Yuen HP, Harrigan SM, Prosser AL et al.: The EPPIC follow-up study of firstepisode psychosis: longer-term clinical and functional outcome 7 years after index admission. J Clin Psychiatry 2010; 71:716-28.

11. Insell TR: The arrival of preemptive psychiatry. Early Interv Psychiatry 2007; 1:5-6.

12. Insel TR: Translating scientific opportunity into public health impact: a strategic plan for research on mental illness. Arch Gen Psychiatry 2009; 66:128-33.

13. Jacobs R: Investigating Patient Outcome Measures in Mental Health. Centre for Health Economics, University of York, York, 2009.

14. Koutsouleris N, Meisenzahl EM, Davatzikos C, Bottlender $R$, Frodl T, Scheuerecker J et al.: Use of neuroanatomical pattern classification to identify subjects in at-risk mental states of psychosis and predict disease transition. Arch Ben Psychiatry 2009; 66:700-12.

15. Larsen TK, Melle I, Auestad B, Friis $S$, Haahr $U$, Johannessen JO et al.: Early detection of first episode psychosis: the effect on 1-year outcome. Schizophr Bull 2006; 32:758-64

16. Lindhardt A: Danish national schizophrenia project. Psychiatric service development in Denmark during the course of DNSP. Eur Psychiatry 2008; 23:49-50.

17. Malla AK, Norman RM, Mancharda R, Ahmed MR, Scholten D, Harricharan $R$ et al.: One year outcome in first episode psychosis: influence of DUP and other predictions. Schizoph Res 2002; 54:231-42.

18. Mangalore $R$ \& Knapp M: Cost of schizophrenia in England. J Ment Health Policy Econ 2007; 109:23-41.

19. Marshall M, Lewis S, Lockwood A, Drake R, Jones P \& Croudace T: Association between duration of untreated psychosis and in cohorts of first episode outcome patients - a systematic review. Arch Gen Psychiatry 2005, 62:975-83.
20. Mason P, Harrison G, Glazebrook C, Medley I, Dalkin T, Croudace TJ: Characteristics of outcome in schizophrenia at 13 years. Br J Psychiatry 1997; 167:596-603.

21. McCrone $P \&$ \&napp M: Economic evaluation of early intervention services. Br J Psychiatry 2007; 51:19-22.

22. McCrone P, Dhanasiri S, Patel A, Knapp M, LawtonSmith S: Paying the price: The Cost of Mental Health Care in England to 2026. The Kings Fund, London, 2008.

23. McGorry P, Purcell R, Hickie I \& Jorm A: Investing in youth mental health is a best buy. Med J Aust 2007; 187:5-22.

24. McGorry P: Evidence, early intervention and the tipping point (editorial). Early Interv Psychiatry 2010; 4:1-3.

25. Meisenzahl EM, Koutsouleris N, Bottlender R, Scheuerecker J, Jäger M, Teipel SJ et al.: Structural brain alterations at different stages of schizophrenia: a voxel-based morphometric study. Schizophr Res 2008a; 104:44-60.

26. Meisenzahl EM, Koutsouleris N, Gaser C, Bottlender R, Schmitt GJ, McGuire P et al.: Structural brain alterations in subjects at high-risk of psychosis: a voxel-based morphometric study. Schizophr Res 2008b; 102:150-62.

27. Melle I, Larsen TK, Haahr U, Friis S, Johannesen JO, Opjordsmoen $S$ et al.: Prevention of Negative Symptom Psychopathologies in First-Episode Schizophrenia: TwoYear Effects of Reducing the Duration of Untreated Psychosis. Arch Gen Psychiatry 2008a; 65:634-40.

28. Molnar S, Restek-Petrović B, Mihanović M, Grošić V, Kezić $S$ \& Grah M: Differences among patients with first episode psychosis and their importance for the program of early intervention. 16th ISPS International Congress, Abstract Book. Copenhagen, 2009; 128.

29. Molnar S, Grošić V, Restek-Petrović B, Mihanović M, Grah M, Kezić $S$ et al.: Obiteljska psihoedukacija kao model rada kod prvih epizoda psihotičnih poremećaja. In Hotujac Lj (ed): Za duh i dušu', 5. hrvatski psihijatrijski kongres, Zbornik radova. Šibenik: Hrvatsko psihijatrijsko društvo, 2010; 130.

30. Nishii H, Yamazawa R, Shimodera S, Suzuki M, Hasegawa $T \&$ Mizuno M: Clinical and social determinants of a longer duration of untreated psychosis of schizophrenia in a Japanese population. Early Interv Psychiatry 2010; 4:182-8.

31. Pantelis C, Velakoulis D, McGorry PD, Wood SJ, Suckling J, Phillips LJ et al.: Neuroanatomical abnormalities before and after onset of psychosis: a crosssectional and longitudinal MRI comparison. Lancet 2003; 361:281-8.

32. Perala J, Suvisaari J, Saarni SI, Kuoppasalmi K, Isometsä E, Pirkola $S$ et al.: Lifetime prevalence of psychotic and bipolar 1 disorders in general population. Arch Gen Psych 2007; 64:19-28.

33. Perkins DO, Gu H, Boteva $K$ \& Lieberman JA: Relationship between duration of untreated psychosis and outcome in first episode schizophrenia: a critical review and metaanalysis. Am J Psychiatry 2005; 162:1785-804.

34. Polari A, Lavoie S, Pascale S, Pellanda V, Cotton SI \& Conus P: Duration of untreated psychosis: a proposition regarding treatment definition. Early Interv Psychiatry 2011; 5:301-8.

35. Preti A, Pisano A, Cascio MT, Galvan F, Monzani E, Meneghelli A et al.: Validation of the Health of the Nation Outcome Scales as a routine measure of outcome in early intervention programmes. Early Interv Psychiatry 2012; $6: 423-31$ 
Branka Restek-Petrović, Ana Majdančić, Sven Molnar, Majda Grah, Ena Ivezić, Igor Filipčić, Anamarija Bogović, Vladimir Grošić, Nina Mayer, Slobodanka Kezić \& Irena Pavlović: EARLY INTERVENTION PROGRAMME FOR PATIENTS WITH PSYCHOTIC DISORDERS IN "SVETI IVAN". PSYCHIATRIC HOSPITAL (RIPEPP) - SOCIODEMOGRAPHIC AND BASELINE CHARACTERISTICS OF THE PARTICIPANTS Psychiatria Danubina, 2017; Vol. 29, No. 2, pp 162-170

36. Restek-Petrović B: Grupna psihoterapija psihoza u ambulantnim uvjetima. In Klain E (ed): Grupna analizaanalitička grupna psihoterapija, 191-204. Medicinska naklada, 2008.

37. Restek-Petrović B, Mihanović M, Grah M, Bogović A, Molnar S, Grošić V et al.: Early intervention in psychosis: A comprehensive hospital outpatient programme for the first episodes during the critical period of illness. Eur Psychiatry 2008; 23 (suppl 2):140.

38. Restek-Petrović B, Grah $M$, Kezić $S$, Mayer $N$ \& Mihanović M: Countertransferential problems in psychodynamic group psychotherapy of young psychotic patients. 16th ISPS International Congress, Abstract Book. Copenhagen, 2009; 37.

39. Restek-Petrović B, Bogović A, Mayer N, Prskalo V, Grah $M$, Kezić $S$ et al.: Correlation between parental bonding and attachment styles in the population of young schizophrenic patients included in Early intervention programme for the psychotic patients in Psychiatric hospital „Sveti Ivan“. Early Interv Psychiatry 2010; 4(suppl 1):73.

40. Restek-Petrović B, Mihanović M, Grah M, Molnar S, Bogović A, Agius $M$ et al: Early Intervention program for psychotic disorders at the Sveti Ivan Psychiatric Hospital. Psychiatr Danub 2012; 24:323-32.

41. Restek-Petrović B, Bogović A, Mihanović M, Grah M, Mayer $N$ \& Ivezić E: Changes in aspects of cognitive functioning in young patients with schizophrenia during group psychodynamic psychotherapy: a preliminary study. Nord J Psychiatry 2014; 68:333-40.

42. Sheitman BB, Lee H, Strauss $R$ \& Liberman JA: The evaluation and treatment of first-episode psychosis. Schizophr Bull 2006; 23:653-61.

43. van Os $J$ \& Kapur M: Schizophrenia. Lancet 2009; 374:23-41.

44. Wunderink L, Sytema S, Nienhuis F\& Wiersma D: Recovery in first episode psychosis. Schizophr Bull 2009; $35: 362-9$.

\section{Correspondence:}

Branka Restek-Petrović, MD, PhD

Psychiatric Hospital "Sveti Ivan"

Jankomir 11, 10000 Zagreb, Croatia

E-mail:branka.restek-petrovic@pbsvi.hr 